\title{
Mycelium-Based Composites as Two-Phase Particulate Composites: Compressive Behaviour of Anisotropic Designs.
}

\section{Adrien Rigobello ( $\sim$ arig@kglakademi.dk )}

The Royal Danish Academy of Fine Arts, School of Architecture, Design and Conservation

\section{Phil Ayres}

The Royal Danish Academy of Fine Arts, School of Architecture, Design and Conservation

\section{Research Article}

Keywords: Mycelium Based Composites (MBC), anistropic substrate designs.

Posted Date: October 11th, 2021

DOl: https://doi.org/10.21203/rs.3.rs-943974/v1

License: (c) (1) This work is licensed under a Creative Commons Attribution 4.0 International License.

Read Full License

Version of Record: A version of this preprint was published at Scientific Reports on April 27th, 2022. See the published version at https://doi.org/10.1038/s41598-022-10930-5. 


\title{
Mycelium-Based Composites as two-phase particulate composites: compressive behaviour of anisotropic designs.
}

\author{
Adrien Rigobello ${ }^{1, *}$ and Phil Ayres ${ }^{1}$ \\ ${ }^{1}$ Centre for IT and Architecture, Royal Danish Academy, Copenhagen, 1435, Denmark. \\ *arig@kglakademi.dk
}

\begin{abstract}
Mycelium Based Composites (MBC) exhibit many properties that make them promising alternatives for less sustainable materials. However, there is no unified approach to their testing. We hypothesise that the two-phase particulate composite model and use of ASTM D1037 could provide a basis for systematisation. An experimental series of MBC were produced using four substrate particle sizes and subjected to compression testing. We report on their effect over Young's modulus and ultimate strength. We extend the study by investigating three anistropic substrate designs through orientated fibre placement as a strategy for modifying compressive behaviour. We find that the two-phase particulate model is appropriate for describing the mechanical behaviour of MBC and that mechanical behaviour can be modified through anisotropic designs using orientated fibres. We also confirm that fibre orientation and particle size are significant parameters in determining ultimate strength.
\end{abstract}

\section{Introduction}

Mycelium-Based Composites (MBC) are being investigated in design and materials engineering by leveraging the saprotrophic lifestyle of ligninolytic fungi, taking inspiration in the XIXth to early XXth century method of fungal strain transfer by lignocellulosic solid-state cultivation ${ }^{1}$. Because MBC cultivation protocols can be based on virtually any substrate containing organic polymers such as lignin, hemicellulose and cellulose, and as they instrumentalise a range of widely available basidiomycota, this class of composite shows potential in obtaining viable products for a variety of uses. Furthermore, MBC conform to circular economy production principles, are expected to be biodegradable, and are assumed to have a low environmental impact in regards to Life-Cycle Assessment (LCA) - although no peer-reviewed studies have been published to date on these aspects. Lignocellulosic substrates cover a variety of geometries and chemical profiles, from industrial grade dusts and particles to supplies of irregular shavings, from grain husks to straws; this variety of supplies has led to the emergence of a rich craft in MBC production. However, this poses a challenge in systematically understanding the behaviour of this new class of materials. We argue that rationalising and systematising approaches to analysing their complexity is necessary to actualise their potential and facilitate market readiness.

No analytical model has been previously proposed for MBC. We hypothesise that they qualify as two-phase particulate composites with the fungal mycelium acting as the matrix, and the substrate, with a high particle content ratio and randomly orientated, acting as the dispersed phase. Because the mechanical response of the fungal mycelium that binds particles together has been qualified as a hyperelastic model ${ }^{2}$, the composite stiffness is primarily driven by the substrate composition. Previous studies of the failure mode of two-phase particulate composites have extensively investigated particle dewetting and their interfacial interactions for high particle content ratios ${ }^{3}$. This study firstly focuses on the influence of particle size on the mechanical behaviour of MBC. The study is then extended to examine the influence of orientated fibres for modifying mechanical behaviour through anisotropic design. Three granulations of beech wood from 0.5 to $12.0 \mathrm{~mm}$ are used and inoculated with a Ganoderma lucidum strain. Across the literature, we find that the lack of a unified approach in the use of analytical models and/or methodological approaches has resulted in inconsistency with specimen design, cultivation and testing protocols. This raises the question of portability and comparability of results. The adoption of the two-phase particulate composite model helped us identify ASTM 1037 as the most appropriate candidate to support the design of specimens and the experimental plan. As a general observation, we found that specimens using particles in the $0.75-3.0 \mathrm{~mm}$ range resulted in a higher performance in compression.

We extended this study to fibre placement strategies with three typologies: rattan fibres perpendicular to load, wheat straw fibres coaxial to load, and hessian jacketing coaxial to load. The addition of fibre coaxial to load had a significant effect over 
Young's elastic modulus and ultimate strength $(\alpha=0.05)$. Fourier-Transform Infrared (FTIR) spectrometry was used to qualify (1) the materials used as principal substrate and fibre addition, (2) the mycelium of G. lucidum, (3) and G. lucidum colonised beech wood. We found that the G. lucidum species degraded primarily lignin and hemicellulose before cellulose, in accordance with previous observations ${ }^{4}$.

Because of the wide range in particle sizes used and fibre composition typologies, the significant difference between specimen groups supports our hypothesis that the two-phase particulate model is suited for future MBC studies $(\alpha=0.005)$. These studies might involve exploring a wider variety of particle shapes, natures, and distributions as these parameters have been shown to have a significant influence over the elastic and plastic behaviour of composites ${ }^{3}$. We demonstrated that the modifying of specimens could be attained with contrasting examples of coaxial reinforcement and perpendicular fracture initiators, with significant effect $(\alpha=0.005)$. However, it should be noted that fibre placements were subjected to variability as fibres could partially misalign with the load axis or its perpendicular during production. This suggests that the standard deviation of the results can be reduced by improving the accuracy in production protocol.

\section{Chemical analysis}

To serve as controls, we used FTIR spectrometry to characterise the four materials used in the composite design (Fig.1). The materials were hemp-based hessian, beech wood, rattan, and common reed. Beech wood and rattan spectra display a chemical profile that is very similar, with the exception of peaks at $1123 \mathrm{~cm}^{-1}$ and $1160 \mathrm{~cm}^{-1}$, and the $1300-1500 \mathrm{~cm}^{-1}$ region. This indicates a slightly higher content of cellulose, hemicellulose and lignin in our tested beech wood specimen $(\mathrm{C}-\mathrm{O}$ stretching, $\mathrm{C}-\mathrm{O}-\mathrm{C}$ asymmetrical stretching, $\mathrm{C}-\mathrm{H}$ deformation, $\mathrm{COOH}$ groups symmetrical stretching, symmetric $\mathrm{C}-\mathrm{H}$ bending, $\mathrm{CH}_{2}$ deformation stretching, $\mathrm{CH}_{3}$ asymmetrical angular vibration, vibrational mode of amide $\mathrm{C}-\mathrm{O}$ stretching $)^{5-7}$. Common reed displays a minimal amount of lignin and hemicellulose compared to our other samples, while the peak at $890 \mathrm{~cm}^{-1}$ is associated with $\mathrm{C}-\mathrm{O}-\mathrm{C}$ stretching at the $\beta$-(1 $\rightarrow 4)$-glycosidic linkages of amorphous cellulose ${ }^{8}$. The hessian displays distinctive peaks at $707 \mathrm{~cm}^{-1}, 890 \mathrm{~cm}^{-1}, 1060 \mathrm{~cm}^{-1}, 1316 \mathrm{~cm}^{-1}$, and $1430 \mathrm{~cm}^{-1}$ in the fingerprint region, and $1640 \mathrm{~cm}^{-1}$, and $2921 \mathrm{~cm}^{-1}$. The $750-680 \mathrm{~cm}^{-1}$ and $1680-1630 \mathrm{~cm}^{-1}$ regions $(\mathrm{C}=\mathrm{O}$ streching) are associated with primary and secondary amides in hemp (amide V: $\mathrm{C}-\mathrm{N}$ and $\mathrm{N}-\mathrm{H}$ vibrations) ${ }^{9}$. Primary amides in hemp are amino acids, fatty acids, and steroids, which contribute to the $3500-3000 \mathrm{~cm}^{-1}$ region. The $1310-1230 \mathrm{~cm}^{-1}$ region $(\mathrm{C}-\mathrm{N}$ stretching) is associated to secondary amides, such as cannabinoids, flavonoids, stilbenoids, terpenoids, alkaloids, and lignans ${ }^{10}$. The peak at $2921 \mathrm{~cm}^{-1}$ is associated with alkyl C-H groups ${ }^{11}$.

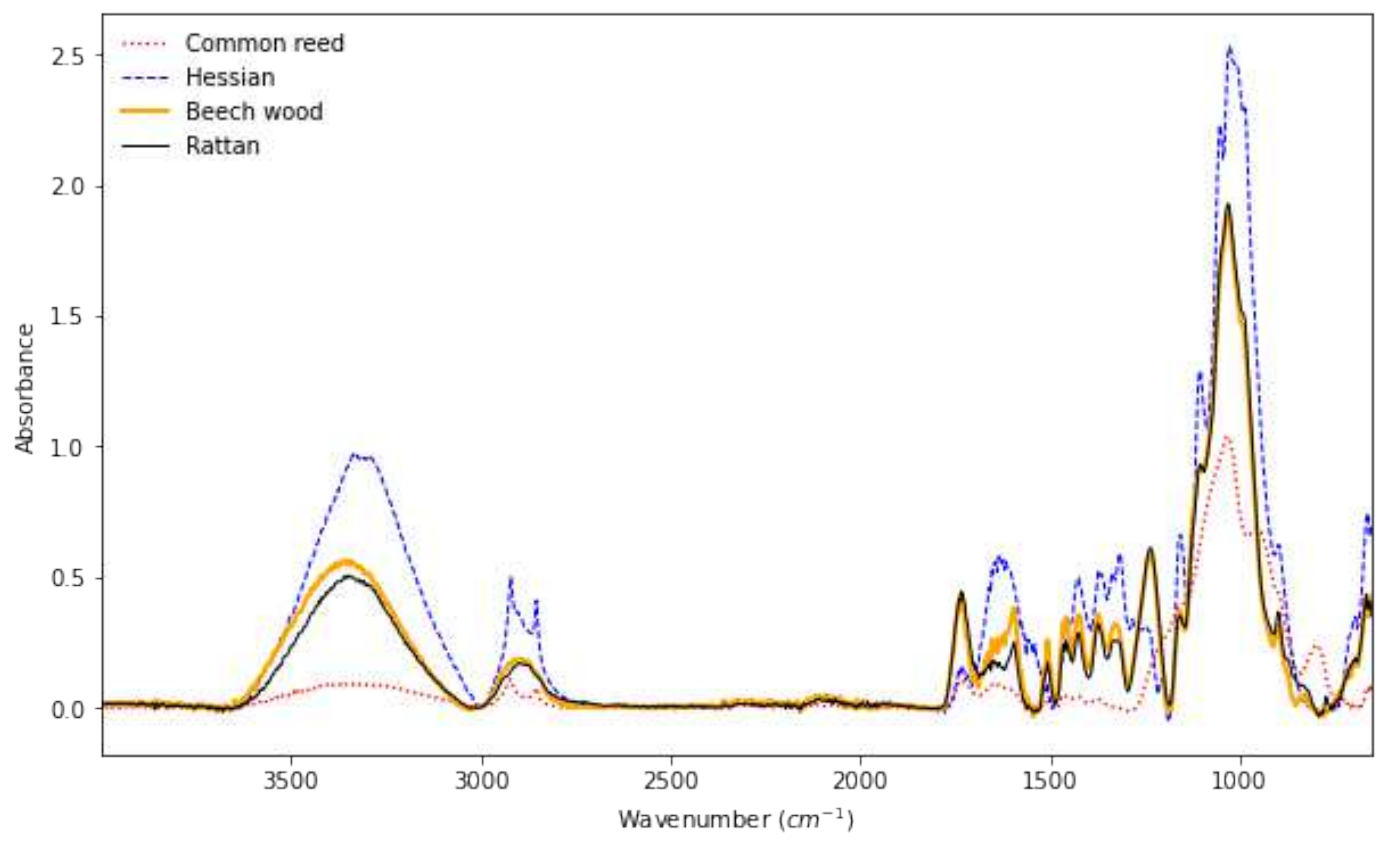

Figure 1. FTIR spectra of hemp-based hessian, beech wood, rattan, and common reed fibres.

Four samples were isolated from G. lucidum colonised beech wood specimens after they were used for load testing. Their spectra were averaged and are presented on Fig.2 along with the beech wood spectrum, and a sample of G. lucidum mycelium. 
Peaks at $886 \mathrm{~cm}^{-1}, 1075 \mathrm{~cm}^{-1}$ and $1160 \mathrm{~cm}^{-1}$ are characteristic of $(1 \rightarrow 3)$ - and $(1 \rightarrow 6)-\beta$-glucans that are present in the fungal cell wall (identified as [2], and [4] on Fig.2). The peaks [1] and [3] at $780 \mathrm{~cm}^{-1}$ and $1043 \mathrm{~cm}^{-1}$ are also associated with $\beta$-glucans ${ }^{12}$. Chitin is identified at peak [5] $1313 \mathrm{~cm}^{-1}$ (amide III: C-N stretching), which also affects the $1640 \mathrm{~cm}^{-1}$ region [6] alongside the presence of peptides and secondary metabolites (aromatic rings and conjugated alkenes). The peak [7] at 2922 $\mathrm{cm}^{-1}$ is representative of chitin and ergosterol $\left(\mathrm{C}-\mathrm{H}\right.$ stretching) ${ }^{13}$. The $3600-3000 \mathrm{~cm}^{-1}$ region (peak [8]) is considered to be influenced by residual water and entrapped $\mathrm{CO}_{2}(\mathrm{O}-\mathrm{H}$ and $\mathrm{N}-\mathrm{H}$ stretching). Finally, peaks [9] to [12] represent decreases at $1231 \mathrm{~cm}^{-1}, 1425 \mathrm{~cm}^{-1}, 1506 \mathrm{~cm}^{-1}$, and $1733 \mathrm{~cm}^{-1}$. They are associated with lignin and xylan breakdown (syringyl ring breathing and $\mathrm{C}-\mathrm{O}$ stretching, $\mathrm{C}=\mathrm{C}$ stretching vibration in aromatic ring), and cellulose (peak [11]) and hemicellulose (peak [11] and [12]) breakdown is observed $\left(\mathrm{CH}_{2} \text { scissor vibration, } \mathrm{C}=\mathrm{O} \text { stretching }\right)^{14}$. To evaluate the lignocellulosic changes undertaken during $G$. lucidum activity quantitatively, the band ratio indices at $1231 \mathrm{~cm}^{-1}, 1425 \mathrm{~cm}^{-1}$, and $1506 \mathrm{~cm}^{-1}$ were calculated from the $2921 \mathrm{~cm}^{-1}$ band ${ }^{15}$ for beech wood and $G$. lucidum colonised beech wood as:

$$
\frac{I_{n}}{I_{2921}}
$$

Where $I_{n}$ is the specific band intensity and $I_{2921}$ the band intensity at $2921 \mathrm{~cm}^{-1}$. The band ratio at $1231 \mathrm{~cm}^{-1}$ went from 1.58 in beech wood to 0.61 in $G$. lucidum colonised beech wood; the band ratio at $1425 \mathrm{~cm}^{-1}$ went from 0.96 in beech wood to 0.63 in G. lucidum colonised beech wood; the band ratio at $1506 \mathrm{~cm}^{-1}$ went from 0.71 in beech wood to 0.24 in $G$. lucidum colonised beech wood; the band ratio at $1733 \mathrm{~cm}^{-1}$ went from 1.19 in beech wood to 0.41 in G. lucidum colonised beech wood. We can therefore observe that $G$. lucidum had a preference in breaking down lignin and xylan at $1231 \mathrm{~cm}^{-1} \mathrm{compared} \mathrm{to}$ cellulose and hemicellulose at $1425 \mathrm{~cm}^{-1}(2.94: 1)$, which is confirmed by the ratios at $1506 \mathrm{~cm}^{-1}$ for lignin (1.42:1), and 1733 $\mathrm{cm}^{-1}$ for hemicellulose (2.36:1). The $\mathrm{CH}_{2}$ scissor vibration corresponding to the peak at $1425 \mathrm{~cm}^{-1}$ reflecting both cellulose and hemicellulose, the present decrease might be primarily related to hemicellulose breakdown. This preference of G. lucidum for lignin and hemicellulose is consistent with findings reported in the literature ${ }^{4}$.

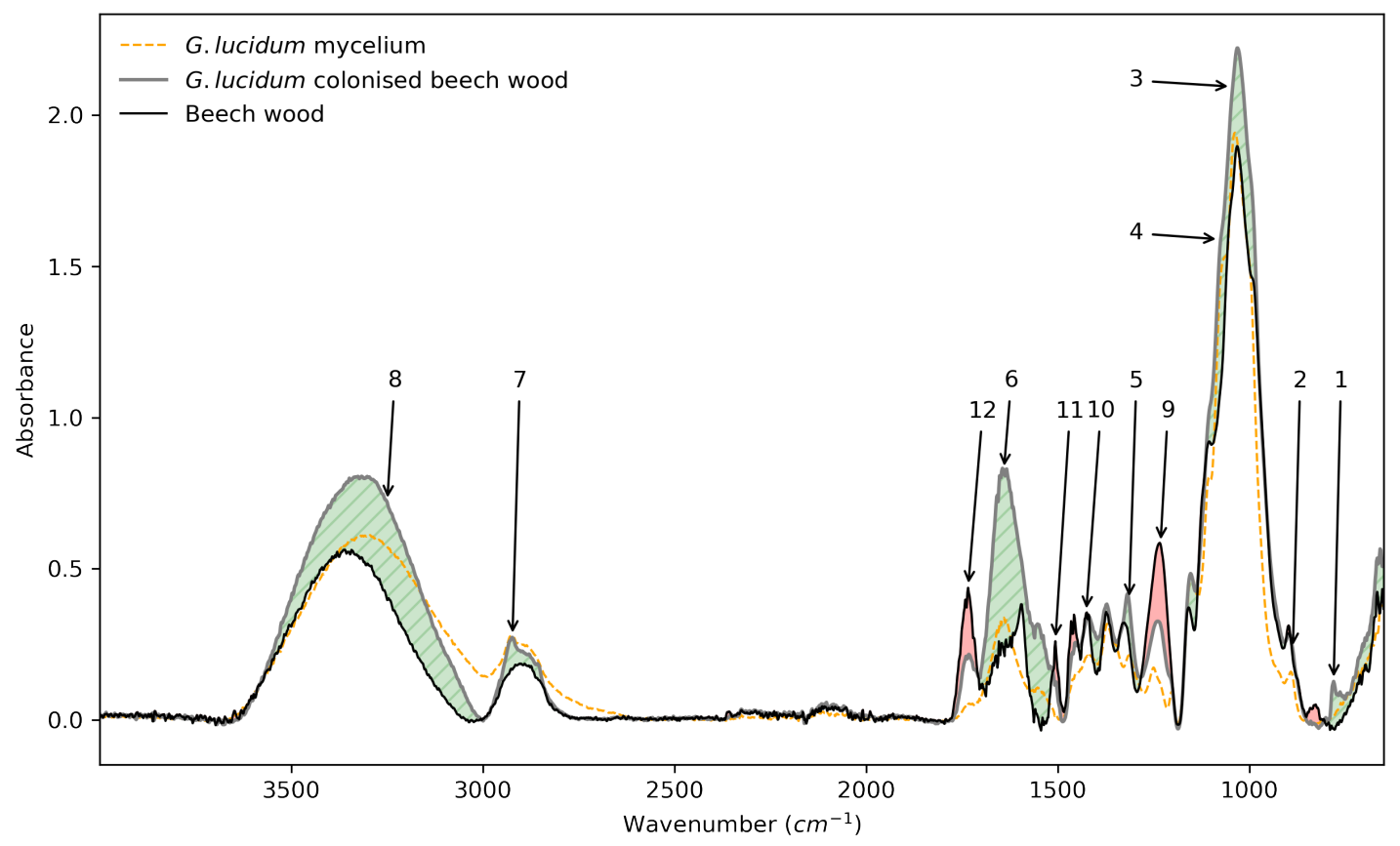

Figure 2. FTIR spectra of G. lucidum colonised beech wood, G. lucidum mycelium, and beech wood. Green areas represent increased values in mycelium-colonised specimens (peaks 1 to 8), red areas are decreased values in mycelium-colonised specimens (peaks 9 to 12). 


\begin{tabular}{|l|l|l||l|l|l|}
\hline Specimen type & Granulate size & Fibre composition & Mean density (s.d.) & Mean Young's modulus (s.d.) & Mean ultimate strength (s.d.) \\
\hline \hline BS & $0.5-1.0 \mathrm{~mm}$ & Control & $209.67 \mathrm{~kg} / \mathrm{m}^{3}(6.47)$ & $1.79 \mathrm{MPa}(0.41)$ \\
BS_H & $0.5-1.0 \mathrm{~mm}$ & Hessian jacketing & $230.48 \mathrm{~kg} / \mathrm{m}^{3}(9.88)$ & $1.58 \mathrm{MPa}(0.42)$ \\
BS_R & $0.5-1.0 \mathrm{~mm}$ & Rattan perpendicular to load & $196.59 \mathrm{~kg} / \mathrm{m}^{3}(19.01)$ & $0.66 \mathrm{MPa}(0.42)$ \\
BS_V & $0.5-1.0 \mathrm{~mm}$ & Common reed coaxial to load & $194.12 \mathrm{~kg} / \mathrm{m}^{3}(5.09)$ & $3.88 \mathrm{MPa}(2.51)$ \\
\hline BM & $0.75-3.0 \mathrm{~mm}$ & Control & $233.87 \mathrm{~kg} / \mathrm{m}^{3}(9.04)$ & $3.32 \mathrm{MPa}(0.80)$ \\
BM_H & $0.75-3.0 \mathrm{~mm}$ & Hessian jacketing & $248.70 \mathrm{~kg} / \mathrm{m}^{3}(12.20)$ & $2.99 \mathrm{MPa}(0.54)$ \\
BM_R & $0.75-3.0 \mathrm{~mm}$ & Rattan perpendicular to load & $226.77 \mathrm{~kg} / \mathrm{m}^{3}(6.19)$ & $4.02 \mathrm{MPa}(4.45)$ \\
BM_V & $0.75-3.0 \mathrm{~mm}$ & Common reed coaxial to load & $198.14 \mathrm{~kg} / \mathrm{m}^{3}(2.89)$ & $9.21 \mathrm{MPa}(6.42)$ \\
\hline BL & $4.0-12.0 \mathrm{~mm}$ & Control & $217.60 \mathrm{~kg} / \mathrm{m}^{3}(10.58)$ & $2.96 \mathrm{MPa}(1.04)$ \\
BL_H & $4.0-12.0 \mathrm{~mm}$ & Hessian jacketing & $264.05 \mathrm{~kg} / \mathrm{m}^{3}(11.97)$ & $3.01 \mathrm{MPa}(0.46)$ \\
BL_R & $4.0-12.0 \mathrm{~mm}$ & Rattan perpendicular to load & $240.98 \mathrm{~kg} / \mathrm{m}^{3}(3.91)$ & $2.24 \mathrm{MPa}(0.58)$ \\
BL_V & $4.0-12.0 \mathrm{~mm}$ & Common reed coaxial to load & $209.47 \mathrm{~kg} / \mathrm{m}^{3}(7.90)$ & $8.50 \mathrm{MPa}(4.56)$ \\
\hline BSML & $0.5-12.0 \mathrm{~mm}$ & Control & $220.59 \mathrm{~kg} / \mathrm{m}^{3}(8.12)$ & $2.17 \mathrm{MPa}(0.36)$ \\
BSML_H & $0.5-12.0 \mathrm{~mm}$ & Hessian jacketing & $246.85 \mathrm{~kg} / \mathrm{m}^{3}(11.29)$ & $2.20 \mathrm{MPa}(1.04)$ \\
BSML_R & $0.5-12.0 \mathrm{~mm}$ & Rattan perpendicular to load & $224.09 \mathrm{~kg} / \mathrm{m}^{3}(3.55)$ & $1.87 \mathrm{MPa}(0.30)$ \\
BSML_V & $0.5-12.0 \mathrm{~mm}$ & Common reed coaxial to load & $203.08 \mathrm{~kg} / \mathrm{m}^{3}(6.24)$ & $7.89 \mathrm{MPa}(2.41)$ \\
\hline
\end{tabular}

Table 1. Summary of specimen types parameters, resulting dried densities, and compressive properties.

\section{Compressive behaviour}

We investigated the effect of particle sizes on the mechanical behaviour in compression of MBC using four levels of granulation: small (BS family), medium (BM family), large particles (BL family), and a 1:1:1 volume ratio mix of the three previous granulations (BSML family). A second parameter was introduced to investigate the anisotrope modification of MBC. Three typologies of fibre composition were implemented in the experimental plan: hessian jacketing coaxial to the load case (H), unidirectional rattan fibres perpendicular to the load case (R), and unidirectional common reed fibres coaxial to the load case (V). Isotropic controls were added for each level of granulation (BS, BM, BL, BSML specimen types in the figures). Fig.3 illustrates the three typologies alongside the control. Experimental parameters per specimen type and resulting mean density, mean Young's modulus and mean ultimate strength are presented in Table 1. Box plots of the results for Young's modulus and ultimate strength are presented in Fig.4, and box plots for densities are reported in Fig. 5.

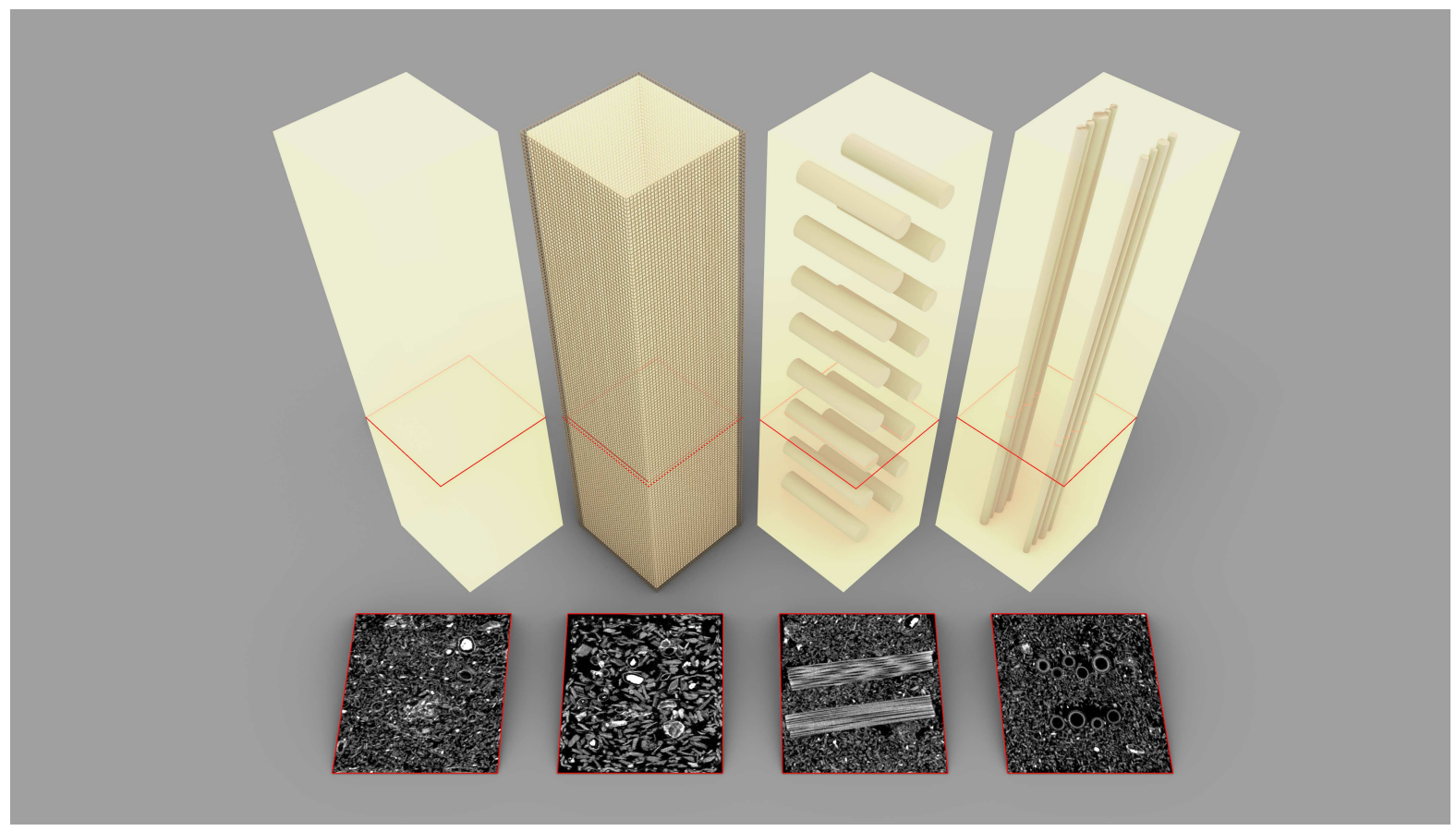

Figure 3. Fibre placement strategies and their sectional CT scan (left to right): control (BS), jacketing coaxial to load (BM_H), fibres perpendicular to load (BS_R), fibres coaxial to load (BS_V). 

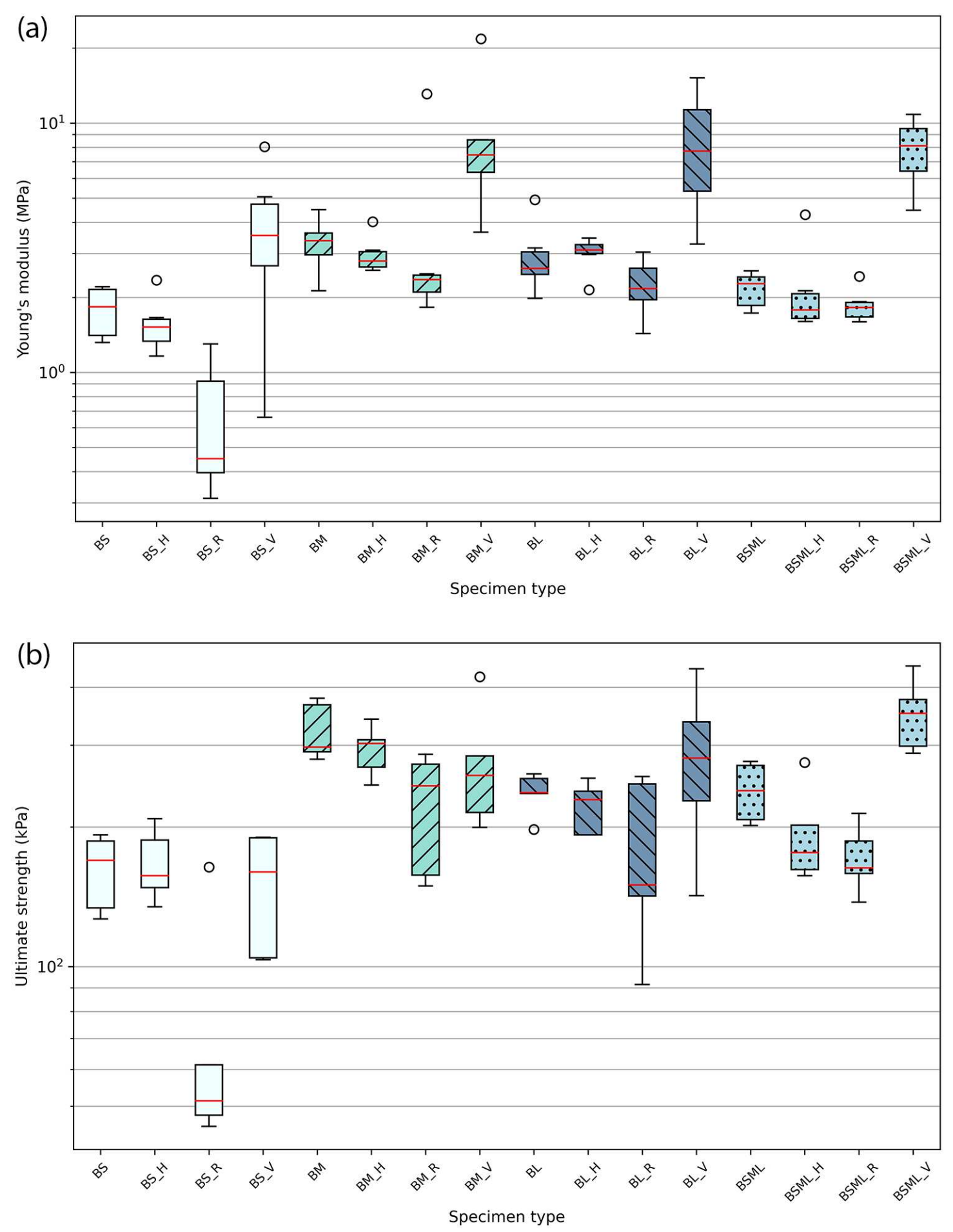

Figure 4. Box plots for Young's modulus results (a) and ultimate strength results (b). 


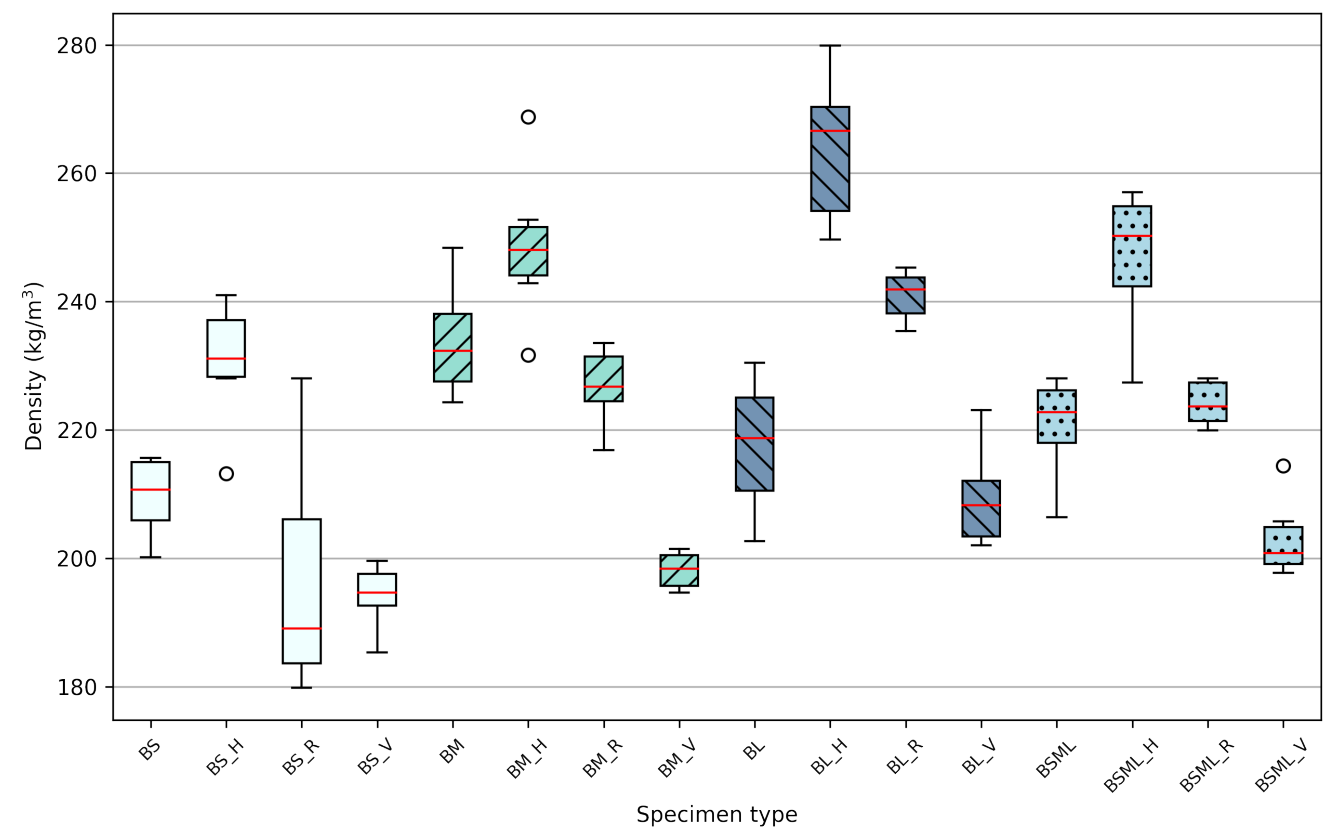

Figure 5. Box plots for dried specimen densities.

\section{Jacketing coaxial to load}

The introduction of the hessian jacket offers a contrasting illustration of the effect of the mycelial mat usually grown on the external boundary of MBC. We observe that the dispersion of Young's modulus results across all specimen families is reduced compared to their controls with the exception of the BL family. The jacketing also affects the dispersion of results in ultimate strength in the case of the BS, BM, and BSML families, with a reduction of the deviation between the first and third quartiles. The containment of stress applied to the specimens within tight boundaries forces the arrangement of the particles within, restricting the ability for particles to arrange freely. Jacketed specimens have an average reduction of $0.12 \mathrm{MPa}$ to the controls as per Young's modulus (s.d. 0.19), and an average decrease of $16.97 \mathrm{kPa}$ to the controls as per ultimate strength (s.d. 20.05). The jacket has two important advantages: it offers a durable alternative to low-ductility mycelial mats usually grown on the external boundary of MBC, and we hypothesise that it can substantially contribute to an increase in fracture resistance performance in shearing and bending load cases.

\section{Fibres perpendicular to load}

Specimens supplemented with rattan fibres display a lower performance across particle sizes considering their median in Young's modulus and ultimate strength. The mean ultimate strength follows the performance of the mean of the controls (Fig.6) with an average reduction of $71.81 \mathrm{kPa}$ (s.d. 8.45). This suggests that, should the production conditions of such MBC improve to reduce the dispersion of results and increase the material behaviour predictability, introducing strategically parsed weakness points in composites could find a use with calibrated materials by tuning their failure mode.

\section{Fibres coaxial to load}

Common reed fibre reinforced specimens resulted in the largest standard deviations in Young's moduli (reported in Table 1), especially in the BM and BL families. This is due to the fibres having partially misaligned to the load case axis during specimen production. Nevertheless, results suggest that MBC can be successfully stiffened with regards to their use case. The effect of this stiffening on the ultimate strength is less obvious as we note that the smaller particles (BS and BM families) tend to perform better without reinforcement coaxial to load. This is a result of the inherent large displacement of the fibres within the specimens under stress due to their stiffness, thus initiating an early critical failure. The mean Young's moduli (Table 1) display a clear improvement compared to the controls: we observe an average increase of a factor 2.86 (s.d. 0.6) between the mean of the controls and the mean of the fibre coaxial to load specimens. As per mean ultimate strengths, they improved in the BL and BSML families when compared to controls (respectively by a factor 1.18 and 1.43), but decreased in the smaller particles families BS and BM (respectively by a factor 0.86 and 0.88 ). 
(a)

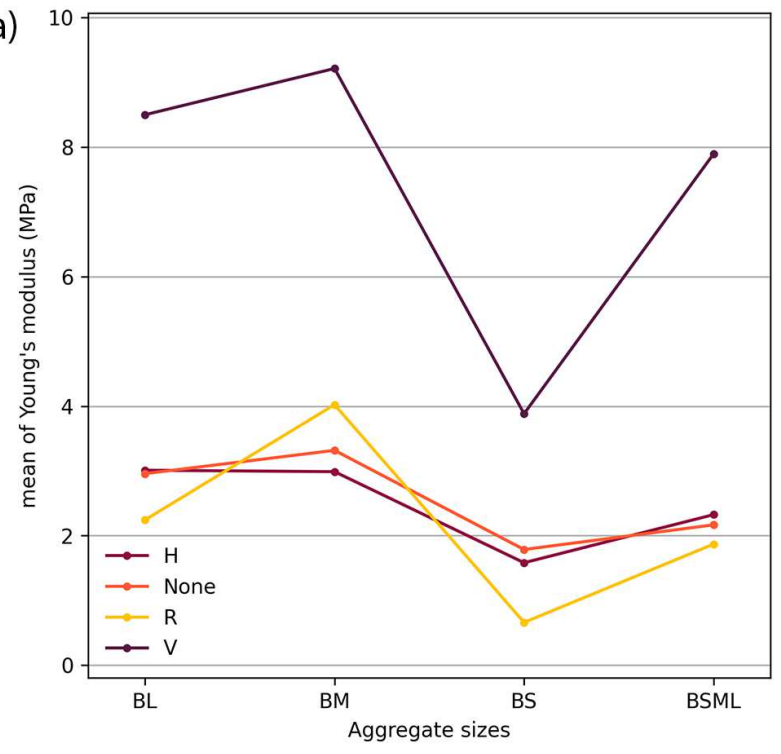

(b)

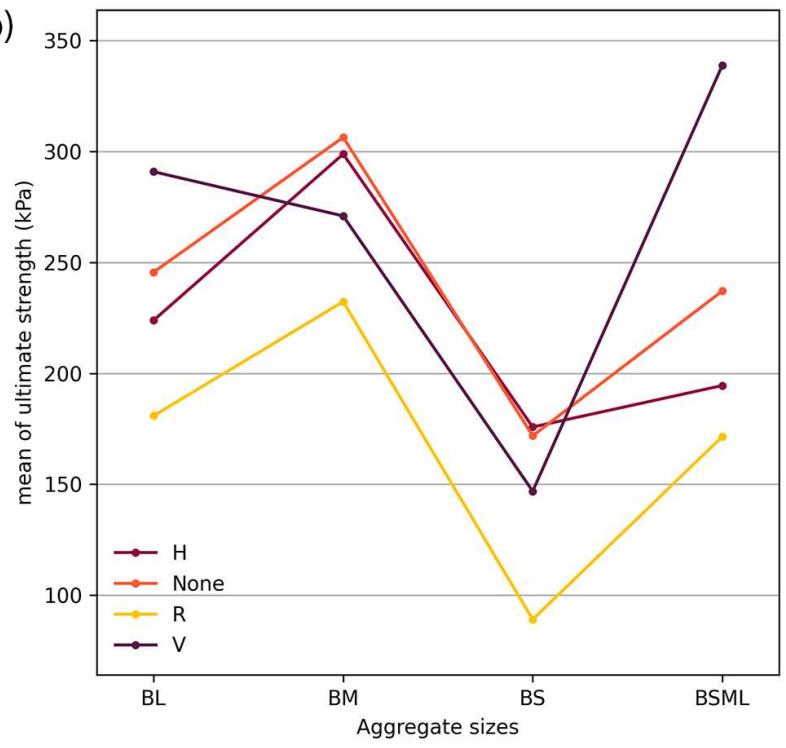

Figure 6. Parameters interaction graph for Young's modulus (a) and ultimate strength (b).

\section{Principal substrate particles}

The use of smaller particles in MBC increases the surface area to volume ratio of what serves as a nutrient for the fungus, hence facilitating its access to it. Fungi also need air access to develop a mycelium, and space between particles, if one desires to have it synthesise a biomass that has a considerable effect over its mechanical properties. The small granulation essentially qualifies as a dust with particles size in the $0.5-1.0 \mathrm{~mm}$ interval, leaving minimal amounts of air between particles within the constrained boundaries of the specimen mould. The best performing BM family (as per ultimate strength) is composed of 0.75 $-3.0 \mathrm{~mm}$ particles, thus embedding particles of a comparable size to the BS dust, while containing particles that are three times as large.

Pure mycelium material response under tensile and compressive stress has been investigated and modelled ${ }^{2}$, and has been classified as an open-cell foam-like material. Pure mycelium is reported to exhibit a Young's modulus of 0.6 - 2 MPa in tension and compression, and an ultimate tensile strength of $100-300 \mathrm{kPa}$. Beech wood, as the principal substrate in this study, has a Young's modulus of $11.9 \mathrm{GPa}$ at $12 \%$ moisture content, and $9.5 \mathrm{GPa}$ when green ${ }^{16}$. Beech wood particles are therefore important load-carrying members of the system and reduce the magnitude of stress experienced by the mycelial matrix. The plastic strain of the composite is contributed to only by particles in such composite, which is clearly exhibited in the range of results in Fig.4. As introduced with the common reed and rattan containing specimens, the dewetting behaviour of the larger particles or reinforcements present in the composite is a principal contributor to damage nucleation. Furthermore, the shape, nature, and distribution of particles in a two-phase composite has been shown to have a substantial influence over the load transfer between members and hence their overall stiffness ${ }^{3}$.

\section{Statistical analysis}

Six replicates were produced and tested for each of the specimen types, the distributions are two-tailed. The mean of Fisher's defined kurtosis for Young's modulus series is -0.3328 (s.d. 0.9353) and -1.0564 for ultimate strength (s.d. 0.5343). FisherPearson's skewness coefficient mean for Young's modulus is 0.5834 (s.d. 0.8540 ), and 0.1733 for ultimate strength (s.d. 0.5137). The distributions are considered normal ${ }^{17}$, which was verified for ultimate strength and Young's modulus results with the Shapiro-Wilk test (respectively $\mathrm{p}=0.9224$ and $\mathrm{p}=0.0030, \alpha=0.001$ ). Equality of variances was therefore controlled with the Levene test; Young's modulus result variances are not equal $(\mathrm{p}=1.3940 \mathrm{e}-5, \alpha=0.05)$, neither are ultimate strength ones $(\mathrm{p}=0.0459, \alpha=0.05)$. Welch's ANOVA was conducted for the two parameters: fibre placement for Young's modulus and ultimate strength (respectively $\mathrm{p}=0.0001$ and $\mathrm{p}=0.0013$ ), and particle size for Young's modulus and ultimate strength (respectively $\mathrm{p}=0.0030$ and $\mathrm{p}=4.6462 \mathrm{e}-9$ ). The mean values of specimen groups are significantly different $(\alpha=0.005)$. Using the pairwise Games-Howell test we identified the most significant reinforcement to be the fibre coaxial to load against fibre perpendicular to load, the control, and hessian jacketing (all $\mathrm{p}=0.001$ as per Young's modulus; respectively $\mathrm{p}=0.030, \mathrm{p}=0.004$, and $\mathrm{p}=0.004$ as per ultimate strength; $\alpha=0.05$ ). Continuing this test, we identified the most significant aggregate size to be the 
$0.5-1.0 \mathrm{~mm}$ interval (BS family) against the BM and BL families (respectively $\mathrm{p}=0.029$ and $\mathrm{p}=0.036$ as per Young's modulus; all $\mathrm{p}=0.001$ as per ultimate strength; $\alpha=0.05$ ). The BS family had a significant difference to the BSML family as per aggregate size over ultimate strength ( $\mathrm{p}=0.001, \alpha=0.05$ ), but not over Young's modulus ( $\mathrm{p}=0.106, \alpha=0.05$ ).

\section{Materials and methods}

\section{Standard reference for specimen design}

A variety of experimental designs are being used in the field of $\mathrm{MBC}$ research and engineering, as there is a current lack of unified approach to the material description. Few studies consider evaluation standards for MBC; among them, ASTM D3501 for wood-based structural panels in compression has been referenced ${ }^{18}$, a standard designed for plywood, wafer-board, orientated strand board, and composites of veneer and of wood-based layers, with use of 2:1 (D:h) cylindrical specimens in the study, instead of rectangular cross-section as the standard advises; ASTM D695 for rigid plastics was also referenced ${ }^{19}$, with a recommended 1:2 (D:h) ratio for cylindrical samples, but used with a diameter of $100 \mathrm{~mm}$ and thickness of $23 \mathrm{~mm}$ in the study; ASTM C67 destined to brick and structural clay tile was referenced in a comparative study against clay bricks ${ }^{20}$, but without following the standard recommendations; and ASTM D2166-13 for cohesive soil was referenced ${ }^{21}$, but deviating from the standard in the study. In requiring the largest particle to be smaller than one tenth of the specimen diameter, the latter ASTM exemplifies the instrumental role these standards can play in systematically investigating materials based on previous studies. The variety of specimen geometries found in the state of the art and lack of consistent recourse to the standards, challenges the portability of, and comparability between, experimental results.

Hypothesising that the best fit model for MBC is as two-phase particulate composite with a high particle content ratio, with particles randomly orientated, and, for this study, with sizes in the $0.5-12.0 \mathrm{~mm}$ range, we identify ASTM D1037 for assessment of wood-base fibre and particle panel materials mechanical properties as the most appropriate material standard for specimen and experimental plan design. We report compression parallel to surface evaluation, for which the short-column method has been chosen as the specimens have of a nominal thickness above $25 \mathrm{~mm}$. They are parallelepipeds of 1:1:4 ratio, the nominal dimensions are $36 \times 36 \times 144 \mathrm{~mm}$ and the dimensions of the dried specimens are $34 \times 34 \times 140 \mathrm{~mm}$. Our experimental plan investigates the effect of granulate sizes and reinforcement strategies over the compressive Young's modulus and ultimate compressive strength.

\section{Principal substrates}

The principal substrates of the specimens originated from European beech wood (Fagus sylvatica). To investigate the effect of particle sizes over the compressive behaviour, we used three granulations (small, medium, large): $0.5-1.0 \mathrm{~mm}$ (Räuchergold type HB 500/1000, J. Rettenmaier \& Söhne GmbH + Co KG, Rosenberg, Germany), 0.75 - 3.0 mm (Räuchergold type HB 750/2000, J. Rettenmaier \& Söhne GmbH + Co KG, Rosenberg, Germany), and 4.0 - 12.0 mm (Räuchergold type KL 2/16, J. Rettenmaier \& Söhne GmbH + Co KG, Rosenberg, Germany). A fourth particle type was added to the experimental plan, as a 1:1:1 volume ratio mix of the three granulations.

\section{Fibre compositions}

Longitudinal fibres were introduced in a specimen series by using common reed fibres (Phragmites australis; Tækkemand Chresten Finn Guld, Køge, Denmark). Eight to ten fibres of $1 \mathrm{~mm} \pm 0.5$ diameter were chosen so as to balance their dimensional variability and positioned in two layers separated by $10 \mathrm{~mm}$ of principal substrate. Fibres perpendicular to compressive stress were studied with use of $6 \mathrm{~mm}$ diameter by $32 \mathrm{~mm}$ length rattan fibres (Calamus manan; B.V. INAPO, Bloemendaal, Netherland). They were positioned regularly within the principal substrate as two layers of fibres, centred in the specimen thickness and separated by a $10 \mathrm{~mm}$ layer of principal substrate. It is common in MBC design practices to have mycelium grown externally on the outer boundaries of the specimens ${ }^{18}$. In the context of this study, no external mycelium was grown so as to observe the effect of granulate sizes and reinforcement strategies without introducing a specimen geometry bias. We identify this bias as critical for the reproducibility of experiments as the characteristics of the external mycelium mat is never found to be reported in the state of the art. In this study, a jacketing strategy has been integrated to study the effect of boundary reinforcement with a reproducible method. Across granulate sizes, a hemp-based hessian jacket (Cannabis sativa subsp. sativa; NEMO Hemp jam web $370 \mathrm{~g} / \mathrm{m}^{2}$, Naturellement Chanvre, Echandelys, France) was introduced on the specimen length. The study complies with relevant institutional, national, and international guidelines and legislation regarding the use of plant materials.

\section{Fungal species}

Trametes spp., Ganoderma spp., and Pleurotus spp. are among the most frequently cited families in MBC design ${ }^{22}$; Schizophyllum commune is a less investigated species but finds a growing interest ${ }^{23}$, and Irpex lacteus has been used previously ${ }^{21} .565$ carbohydrate-active enzyme families (CAZymes) have previously been assigned to the $G$. lucidum species ${ }^{4,24}$, representing 
the widest array from hydrolytic enzymes (hydrolysis of hemicellulose, pectin), to oxidoreductases (laccases, ligninolytic peroxidases and peroxide-generating oxidases), to cellobiose dehydrogenase. Because this species is considered a very versatile ligninolytic fungus, in that it can exploit various strategies for the breakdown of lignin and can ultimately degrade all components of lignocellulosic compounds, it was selected for implementing the experimental plan. A millet-grown spawn of ligninolytic species Ganoderma lucidum (reference M9726) was acquired from Mycelia BVBA (Nevele, Belgium). The spawn was stored at a constant $4{ }^{\circ} \mathrm{C}$ and $65 \%$ relative humidity (RH).

\section{Specimen preparation}

The moisture content (MC) within cell walls as bound water, and outside cell walls in wood void structure as capillary water or vapour, is critical for understanding and predicting fungal activity ${ }^{25}$. In MBC production, lignocellulosic substrates composed of particle or fibres have a MC that is homogeneously prepared at $55-70 \%{ }^{18,26}$, and the use of mineralized to sterile demineralized water has been documented as a moisturising mean ${ }^{18,26,27}$.

For this study, the principal substrates, fibres and hessian were prepared at $70 \% \mathrm{MC}$ with mineralized water, and sterilised at $121^{\circ} \mathrm{C}$ for $15 \mathrm{~min}$. The principal substrates were then mixed with $16 \mathrm{wt} \% \mathrm{G}$. lucidum spawn and incubated in PP filtered bags (PPD50/REH4+1/V22-49, SacO2, Deinze, Belgium) for 7 days at $25^{\circ} \mathrm{C}$ in the dark. Once colonised, the principal substrates were massaged to break them down and formed with the fibres and hessian into aerated PETG moulds. The formed specimens were incubated for 21 days at $25^{\circ} \mathrm{C}$ in the dark, then oven dried for 48 hours at $60^{\circ} \mathrm{C}$. The dried specimens were stored at $4{ }^{\circ} \mathrm{C}$ and $65 \%$ RH prior to testing.

\section{Compressive behaviour characterisation}

The use of seismic waves to characterise the mechanical behaviour of $\mathrm{MBC}$ has been reported in the literature as an alternative to conventional uniaxial load testing ${ }^{21}$. This method has become common in geological and civil engineering, and offers the benefit of being non-destructive. However, the anisotropic nature of the composite matrix (the mycelium), together with is its high elasticity, causes waves to attenuate irregularly. Furthermore, $\mathrm{MBC}$ have such a high porosity and a high variation in particle sizes and distribution that gaining accurate measurements would be challenging. This is evidenced in the literature by a larger standard deviation in results using this process applied to homogeneous $\mathrm{MBC}^{21}$. In the context of this study, load testing was performed on a Mecmesin MultiTest-dV testing bench equipped with a $2500 \mathrm{~N}$ load sensor, with a loading speed of 1.0 $\mathrm{mm} / \mathrm{min}$. Young's modulus and ultimate compressive strength were calculated following ASTM D1037.

\section{Chemical analysis}

Fourier-Transform Infrared (FTIR) spectrometry has been used previously for analysing the lignocellulosic profiles of substrates and their relation to fungal degradation patterns ${ }^{18,28-30}$, with the benefit of requiring a limited specimen preparation, and spectra shape and frequencies being directly related to microscopical physical quantities and hence prepared for interpretation ${ }^{31}$. FTIR spectrometry was conducted in this study on a single reflection diamond Attenuated Total Reflectance (ATR) Agilent 4500a FTIR (Santa Clara, USA). The acquisition resolution was $4 \mathrm{~cm}^{-1}$ with 16 scans per specimen, for a band between $4000 \mathrm{~cm}^{-1}$ and $650 \mathrm{~cm}^{-1}$. We corrected the baseline of FTIR spectra following the adaptive iteratively reweighted Penalised Least Squares (airPLS) method ${ }^{32}$, and spectra normalization was done with amide I/II band envelopes ${ }^{33}$. Four samples were isolated from $G$. lucidum colonised beech wood specimens, their spectra were averaged for analysis. The other specimens were tested with one replicate.

\section{References}

1. Duggar, B. M. The Principles of Mushroom Growing and Mushroom Spawn Making (U.S. Government Printing Office).

2. Islam, M. R., Tudryn, G., Bucinell, R., Schadler, L. S. \& Picu, C. R. Stochastic continuum model for mycelium-based bio-foam. 160, 549-556, DOI: 10.1016/j.matdes.2018.09.046.

3. Shen, Y.-L., Finot, M., Needleman, A. \& Suresh, S. Effective elastic response of two-phase composites. 42, 77-97, DOI: 10.1016/0956-7151(94)90050-7.

4. Zhou, S. et al. Investigation of lignocellulolytic enzymes during different growth phases of ganoderma lucidum strain g0119 using genomic, transcriptomic and secretomic analyses. 13, e0198404, DOI: 10.1371/journal.pone.0198404. Publisher: Public Library of Science.

5. Bekiaris, G., Tagkouli, D., Koutrotsios, G., Kalogeropoulos, N. \& Zervakis, G. I. Pleurotus mushrooms content in glucans and ergosterol assessed by ATR-FTIR spectroscopy and multivariate analysis. 9, 535, DOI: 10.3390/foods9040535.

6. Li, X., Wei, Y., Xu, J., Xu, N. \& He, Y. Quantitative visualization of lignocellulose components in transverse sections of moso bamboo based on FTIR macro- and micro-spectroscopy coupled with chemometrics. 11, 263, DOI: 10.1186/ s13068-018-1251-4. 
7. Shi, J., Xing, D. \& Lia, J. FTIR studies of the changes in wood chemistry from wood forming tissue under inclined treatment. 16, 758-762, DOI: 10.1016/j.egypro.2012.01.122.

8. Ciolacu, D., Ciolacu, F. \& Popa, V. I. Amorphous cellulose - structure and characterization. 45, 13-21.

9. Smith, B. C. Organic nitrogen compounds, VII: Amides - the rest of the story. In Spectroscopy, vol. 35, 10-15.

10. Flores-Sanchez, I. J. \& Verpoorte, R. Secondary metabolism in cannabis. 7, 615-639, DOI: 10.1007/s11101-008-9094-4.

11. Dorado, J., Almendros, G., Field, J. \& Sierra-Alvarez, R. Infrared spectroscopy analysis of hemp (cannabis sativa) after selective delignification by bjerkandera sp. at different nitrogen levels. 28, 550-559, DOI: 10.1016/S0141-0229(00) 00363-X.

12. Šandula, J., Kogan, G., Kačuráková, M. \& Machová, E. Microbial $(1 \rightarrow 3)$--d-glucans, their preparation, physico-chemical characterization and immunomodulatory activity. 38, 247-253, DOI: 10.1016/S0144-8617(98)00099-X.

13. Girometta, C. et al. Physico-mechanical and thermodynamic properties of mycelium-based biocomposites: A review. 11, 281, DOI: 10.3390/su11010281. Number: 1 Publisher: Multidisciplinary Digital Publishing Institute.

14. Cai, Q. et al. Dissolving process of bamboo powder analyzed by FT-IR spectroscopy. 1171, DOI: 10.1016/j.molstruc. 2018.06.066.

15. Diehl, S. V., Prewitt, M. L. \& Shmulsky, F. M. Use of fatty acid profiles to identify white-rot wood decay fungi. In Wood Deterioration and Preservation, vol. 845 of ACS Symposium Series, 313-324, DOI: 10.1021/bk-2003-0845.ch017 (American Chemical Society). Section: 17.

16. Green, D. W., Winandy, J. E. \& Kretschmann, D. E. Mechanical properties of wood. 113.

17. Hair, J. F., Black, W. C., Babin, B. J. \& Anderson, R. E. Multivariate Data Analysis (Pearson Education Limited).

18. Elsacker, E., Vandelook, S., Brancart, J., Peeters, E. \& Laet, L. D. Mechanical, physical and chemical characterisation of mycelium-based composites with different types of lignocellulosic substrates. 14, e0213954, DOI: 10.1371/journal.pone. 0213954. Publisher: Public Library of Science.

19. Sivaprasad, S., Byju, S. K., Prajith, C., Shaju, J. \& C R, R. Development of a novel mycelium bio-composite material to substitute for polystyrene in packaging applications. DOI: 10.1016/j.matpr.2021.04.622.

20. Ongpeng, J., Inciong, E., Siggaoat, A., Soliman, C. A. \& Sendo, V. B. Using waste in producing bio-composite mycelium bricks. 10, DOI: 10.3390/app10155303.

21. Yang, Z., Zhang, F., Still, B., White, M. \& Amstislavski, P. Physical and mechanical properties of fungal mycelium-based biofoam. 29, 04017030, DOI: 10.1061/(ASCE)MT.1943-5533.0001866.

22. Attias, N. et al. Mycelium bio-composites in industrial design and architecture: Comparative review and experimental analysis. 246, 119037, DOI: 10.1016/j.jclepro.2019.119037.

23. Appels, F. V. W., van den Brandhof, J. G., Dijksterhuis, J., de Kort, G. W. \& Wösten, H. A. B. Fungal mycelium classified in different material families based on glycerol treatment. 3, 1-5, DOI: 10.1038/s42003-020-1064-4. Number: 1 Publisher: Nature Publishing Group.

24. Chen, S. et al. Genome sequence of the model medicinal mushroom ganoderma lucidum. 3, 913, DOI: 10.1038/ ncomms 1923.

25. Engelund, E. T., Thygesen, L. G., Svensson, S. \& Hill, C. A. S. A critical discussion of the physics of wood-water interactions. 47, 141-161, DOI: 10.1007/s00226-012-0514-7.

26. Appels, F. V. W. et al. Fabrication factors influencing mechanical, moisture- and water-related properties of mycelium-based composites. 161, 64-71, DOI: 10.1016/j.matdes.2018.11.027.

27. Jones, M., Mautner, A., Luenco, S., Bismarck, A. \& John, S. Engineered mycelium composite construction materials from fungal biorefineries: A critical review. 187, 108397, DOI: 10.1016/j.matdes.2019.108397.

28. Pandey, K. K. \& Pitman, A. J. FTIR studies of the changes in wood chemistry following decay by brown-rot and white-rot fungi. 52, 151-160, DOI: 10.1016/S0964-8305(03)00052-0.

29. Pandey, K. K. A study of chemical structure of soft and hardwood and wood polymers by FTIR spectroscopy. 71, 1969-1975, DOI: 10.1002/(SICI)1097-4628(19990321)71:12<1969::AID-APP6>3.0.CO;2-D.

30. Haneef, M. et al. Advanced materials from fungal mycelium: Fabrication and tuning of physical properties. 7, 1-11, DOI: 10.1038/srep41292.

31. Grdadolnik, J. ATR-FTIR spectroscopy: Its advantages and limitations. 49, 631-642. 
32. Zhang, Z.-M., Chen, S. \& Liang, Y.-Z. Baseline correction using adaptive iteratively reweighted penalized least squares. 135, 1138-1146, DOI: 10.1039/b922045c.

33. Baker, M. J. et al. Using fourier transform IR spectroscopy to analyze biological materials. 9, 1771-1791, DOI: 10.1038/nprot.2014.110.

\section{Acknowledgements}

This project has received funding from the European Union's Horizon 2020 research and innovation program FET OPEN "Challenging current thinking" under grant agreement No 858132. The authors declare no conflict of interest. The funding bodies had no role in the design of the study; in the collection, analyses, or interpretation of data; in the writing of the manuscript, or in the decision to publish the results.

\section{Author contributions statement}

A.R. and P.A. conceived the experiments, A.R. conceived the methodology, A.R. and P.A. conducted the experiments, A.R. analysed the results. All authors reviewed the manuscript. 